\title{
TRAIL-induced apoptosis and expression of death receptor TRAIL-R1 and TRAIL-R2 in bladder cancer cells
}

\author{
Ewelina Szliszka, Bogdan Mazur, Grzegorz Żydowicz, Zenon P. Czuba, \\ Wojciech Król*
}

Chair and Department of Microbiology and Immunology, Zabrze, Medical University of Silesia in Katowice, Poland

\begin{abstract}
Tumor necrosis factor-related apoptosis-inducing ligand (TRAIL/Apo2L) is a member of TNF superfamily able to induce programmed death in cancer cells with no toxicity against normal tissues. TRAIL mediate apoptosis follows binding to the two death receptors, TRAIL-R1 (DR4) and/or TRAIL-R2 (DR5). In this study we investigated the cytotoxic and apoptotic effect of TRAIL on bladder cancer cells and the expression of death receptor TRAIL-R1 and TRAIL-R2 on the surface of these cancer cells. Three human bladder transitional cancer cell (TCC) lines - SW780, 647V and T24 were tested for TRAIL sensitivity. The bladder cancer cells were incubated with human soluble recombinant TRAIL. Cytotoxicity was measured by MTT (3-[4,5-dimethylthiazol-2-yl]-2,5-dimethyltetrazolium bromide) and LDH (lactate dyhydrogenase) assays. Apoptosis was detected by flow cytometry with annexin V-FITC/propidium iodide and by fluorescence microscopy with Hoechst 33342/annexin V-FITC/Ethidium Homodimer. The cell surface expression of TRAIL death receptors on bladder cancer were determined using flow cytometry with phycoerythrin-conjugated monoclonal anti-human TRAIL-R1 and TRAIL-R2. Our investigations confirmed that SW780 cells were sensitive to TRAIL, and two other bladder cancer cell lines, 647V and T24, were resistant to TRAIL induced apoptosis. We therefore examined the expression of TRAIL death receptors on bladder cancer cell surfaces. We showed decreased expression of TRAIL-R2 receptor in TRAIL-resistant bladder cancer cells and increased expression of this death receptor in TRAIL-sensitive SW780 cells. The expression of TRAILR1 receptor was similar in all bladder cancer cell lines. TRAIL is one of the promising candidates for cancer therapeutics. However, some cancer cells are resistant to TRAIL-mediated apoptosis. It is therefore important to overcome this resistance for the clinical use of TRAIL in cancer therapy. TRAIL death receptors are attractive therapeutic targets in cancer treatment. The cytotoxic agents capable of up-regulating the expression of TRAIL-R1 and TRAIL-R2 can sensitize cancer cells to TRAIL induced apoptosis.
\end{abstract}

Key words: apoptosis, TRAIL, TRAIL-R1, TRAIL-R2, bladder cancer cells

\section{Introduction}

Apoptosis is a genetically programmed cell death controlled by two diverse pathways, the receptor-mediated (extrinsic) pathway and the mitochondrial-mediated (intrinsic) pathway [1]. There are numerous ligands of TNF (tumor necrosis factor) superfamily that are involved in apoptosis. Some members of this family are TNFo, FasL/Apo1L/CD95L and TRAIL/Apo2L/ TNFSF10. They regulate many biological functions

Correspondence: W. Król, Chair and Department of Microbiology and Immunology, Zabrze, Medical University of Silesia in Katowice, 41-808 Zabrze, H. Jordana Str. 19, Poland; tel./fax.: (+4832) 2722554, e-mail: wkrol@sum.edu.pl including cell metabolism, proliferation, cytokine production and apoptosis. Failure to undergo apoptosis has been implicated in tumor development and resistance to cancer therapy [1-3].

Tumor necrosis factor-related apoptosis-inducing ligand (TRAIL) was originally identified in 1995 and cloned on the basis of sequence homology to the FasL and TNF [4]. TRAIL is characterized as a powerful activator of programmed cell death in tumor cells with no toxicity against normal tissues [5]. This feature has greatly spurred research to explore the potential of TRAIL as an anticancer therapy and the mechanisms underlying its antitumor properties [6,7]. Endogenous TRAIL exerts biological activity as an integral membrane (type II transmembrane) protein expressed on 
the surface of immune cells or soluble form, which is released by immune cells. Both full-length membrane expressed TRAIL and the soluble ligand can rapidly induce apoptosis in a wide variety of human cancer cells and xenographic tumor models [6-9].

TRAIL binds to five receptors: four type I transmembrane proteins TRAIL-R1,-R2,-R3,-R4 and one soluble receptor (OPG). Among the various receptorligand interactions possible within the TNF superfamily, the TRAIL ligand-receptors system is the most complex [10]. Two of these transmembrane receptors, namely death receptor TRAIL-R1 (DR4) and death receptor TRAIL-R2 (DR5, KILLER), contain death domain (DD) through which TRAIL transmits an apoptotic signal. TRAIL triggers apoptosis via interaction with TRAIL death receptors present in target cells. This intracellular DD of TRAIL-R1 and TRAIL-R2 have been found to be essential for induction of apoptosis following receptor ligation $[11,12]$. Two other transmembrane receptors, called decoy receptors TRAIL-R3 (DcR1) and TRAIL-R4 (DcR2) and one soluble receptor, osteprotegerin (OPG) lacking a functional DD, act as antagonistic receptor competing with death receptors TRAIL-R1 and TRAIL-R2 for binding to the TRAIL. Decoys receptors and OPG are involved in negative regulation of apoptosis by sequestering TRAIL and stimulating prosurvival signals [13].

TRAIL binds as a homotrimer to TRAIL-R1 and TRAIL-R2, which results in trimerisation of the death receptors and subsequent assembly of a death-inducing signaling complex (DISC). At the DISC, the adaptor protein FAAD (Fas-associated-death domain) acts as a bridge between the death receptor complex and the initiator caspase 8. Upon recruitment by FADD, caspase 8 will be activated and then activates downstream effector caspases such as caspases 3, 6 and 7, which execute apoptosis. This death receptor initiated apoptosis pathway is referred to as the extrinsic apoptosis pathway. Crosstalk exists between the extrinsic pathway and the intrinsic one called mitochondrial-initiated apoptosis pathway through Bid. Caspase- 8 also mediates also cleavage of Bid (BH3-interacting domain death agonist). Trucated Bid called tBid translocates to the mitochondria where it interacts with Bax (Bcl-2-associated X protein) and Bak (Bcl-2-agonist/killer), stimulating the release of cytochrome $c$. In the cytosol, cytochrome $c$ binds the adaptor protein Apaf-1 (apoptotic protease-activating factor-1) and procaspase-9, forming the apoptosome and activating caspase-9 which in turn activates executioner caspases (caspase-3, -6, -7) leading to apoptosis $[1,6,14]$.

Bladder cancer is the fourth most common malignancy in men and eighth most common malignancy in women. Transitional cell carcinoma (TCC) is observed in above $90 \%$ of pathologic subtypes of bladder tumors. A novel therapeutic strategies are required to prevent bladder cancer recurrence and reduce risk of tumor progression [15].

Targeting death receptors to trigger apoptosis in tumor cells is an attractive concept for cancer therapy including bladder tumors [16]. TRAIL appears to be a relatively safe and promising candidate for clinical application. Currently, phase I and phase II studies are being initiated with human recombinant TRAIL or agonistic monoclonal antibodies against TRAIL-R1 and/or TRAIL-R2 $[14,17,18]$.

However, some cancer cells are resistant to TRAIL induced apoptosis. The mutation or decreased expression of death receptors (TRAIL-R1 and/or TRAIL-R2) and increased expression of antiapoptotic protein in cancer cells are involved in TRAIL-resistance $[19,20]$. The combined treatment with TRAIL and anticancer agents, such as chemotherapeutic drugs or ionizing radiation, can overcome TRAIL-resistance and sensitize cancer cells to TRAIL-mediated programmed cell death [21].

\section{Materials and methods}

Reagents. Recombinant human TRAIL was purchased from PeproTech Inc. (Rocky Hill, NJ, USA).

Cell culture. The experiments were performed on three human bladder transitional cancer cell (TCC) lines derived from bladder tumor obtained from DSMZ (German Collection of Microorganisms and Cell Cultures, Braunschweig, Germany) and ATCC (American Type Culture Collection, Manassas, VA, USA):

- SW780 line cells, cat. no. CRL-2169 - well differentiated transitional cells $(\mathrm{G} 1)$,

- 647 line cells, cat. no. ACC-414 - moderately differentiated transitional cells (G2),

- T24 line cells, cat. no. ACC-376 - poorly differentiated transitional cells $(\mathrm{G} 3)$.

The bladder cancer cells were grown in monolayer cultures in $75 \mathrm{~cm}^{2}$ plastic flasks (Nunc A/S Roskilde, Denmark): SW780 cells in Leibovitz's, 647V and T24 cells in DMEM. All mediums were supplemented with $10 \%$ of heat-inactivated fetal bovine serum (FBS), $2 \mathrm{mM}$ L-glutamine, $100 \mathrm{U} / \mathrm{ml}$ penicillin, and $100 \mu \mathrm{g} / \mathrm{ml}$ streptomycin. The cells were incubated at $37^{\circ} \mathrm{C}$, SW780 cells in $100 \%$ air atmosphere, $647 \mathrm{~V}$ and T24 cells in $95 \%$ air atmosphere and $5 \% \mathrm{CO}_{2}$. TCC cells were passaged three times a week. During the experiments, cells were detached with $0.05 \%$ trypsin/ $0.02 \%$ EDTA. Reagents for bladder cancer cell culture were purchased from PAA The Cell Culture Company (Pasching, Austria). The density of bladder cancer cells in each test was $1 \times 10^{6} / \mathrm{ml}$ for SW780 cells and $0.5 \times 10^{6} / \mathrm{ml}$ for $647 \mathrm{~V}$ and T24 cells.

MTT assay. The cytotoxic effect of TRAIL on bladder cancer cells was measured by MTT (3-[4,5-dimethylthiazol-2-yl]-2,5diphenyltetrazolium) assay, as described $[22,23]$. TCC cells were seeded onto a 96-well plate (Nunc A/S Roskilde, Denmark) 24 hours before the experiments. Various concentrations of rhsTRAIL were added to the cells, and 20 hours later the medium was removed and $20 \mu \mathrm{l}$ MTT solutions $(5 \mathrm{mg} / \mathrm{ml}$ ) (Sigma Chemical Company, MO, USA) were added to each well for 4 hours. The resulting crystals were dissolved in DMSO (Sigma Chemical Company, MO, USA). Controls included native cells and medium alone. The spectrophotometric absorbance of each well was measured using a microplate reader (ELx 800, Bio-Tek Instruments Inc., 
Winooski, VT, USA) with a test wavelength of $550 \mathrm{~nm}$. The data on the cell proliferation and cytotoxic assays was obtained from three separate experiments and for each test quadruplicate wells were used. The percent cytotoxicity was calculated by the following formula: percent cytotoxicity $($ cell death $)=(1-$ [absorbance of experimental wells/absorbance of control wells] $) \times 100 \%$.

LDH release assay. LDH (lactate dehydrogenase) is a stable cytosolic enzyme that is released upon membrane damage. LDH activity was measured using a commercial cytotoxicity assay kit (Roche Diagnostics GmbH, Mannheim, Germany), in which LDH released in culture supernatants is measured with a coupled enzymatic assay, resulting in conversion of a tetrazolium salt into red formazan product. The bladder cancer cells were treated with various concentrations of rhsTRAIL for the indicated period of time. The sample solution (supernatant) was removed and LDH released from cells was measured in culture medium. The maximal release was obtained after treating control cells with $1 \%$ Triton X-100 (Sigma Chemical Company, St. Louis, MO) for 10 minutes at room temperature [22]. The necrotic percentage was expressed using the formula, (sample value/maximal release) $\times 100 \%$.

Determination of apoptotic cell death by flow cytometry with annexin V-FITC staining. Apoptosis was measured using flow cytometry to quantify the levels of decentable phosphatidylserine (PS) on the outer membrane of apoptotic cells. Externalized PS on the outer surface of the cytoplasmic membrane becomes labeled by fluoresceinlabeled annexin $\mathrm{V}$, which has a high affinity for PS-containing phospholipids bilayers. Bladder cancer cell lines were seeded in 24-well plates for 24 hours and then exposed to rhsTRAIL for 20 hours. After a 20 hour incubation TCC cells were washed twice with PBS and resuspended in $1 \mathrm{ml}$ of binding buffer. Five hundred microliters of cell suspension was then incubated with $5 \mu \mathrm{l}$ of annexin V-FITC and $10 \mu \mathrm{l}$ of propidium iodide (PI) for $10 \mathrm{~min}$ at room temperature in the dark. Annexin V assay was performed using the Apoptotest-FITC Kit (Dako, Glostrup, Denmark). The population of annexin V-positive cells was evaluated by flow cytometry (BD FACScan, Becton Dickinson Immnunocytometry Systems, San Jose, CA, USA) [24].

Determination of apoptotic cell death by fluorescence microscopy with annexin V-FITC staining. Apoptotic cells were quantified by fluorescence microscopic method using Apoptotic \& Necrotic \& Healthy Cells Quantification Kit from Biotium, Inc. (Hayward, CA, USA) according to the manufacturer's instruction [25]. Bladder cells were washed with PBS and detached from cell culture wells by trypsin. Next, the TCC cells were centrifuged to discard supernatant, washed with PBS and resuspended in Binding Buffer $(100 \mu \mathrm{l} / \mathrm{sample})$. To each tube were added: $5 \mu \mathrm{l}$ of FITCAnnexin V, $5 \mu \mathrm{l}$ of ethidium homodimer III and $5 \mu \mathrm{l}$ of Hoechst 33342 solutions. The samples were incubated at room temperature for 15 minutes in the dark. After staining the cells were washed with Binding Buffer and placed on a glass slide and covered with a glass coverslip. The stained cells were observed under a fluorescence inverted microscope IX51 (Olympus, Tokyo, Japan) using filter set for FITC, TRITC and DAPI. The healthy cells (stained by Hoechst 33342) emitted blue fluorescence, apoptotic cells (stained by FITC-Annexin V and Hoechst 33342) emitted green and blue fluorescence and necrotic cells (stained with ethidium homodimer III and Hoechst 33342) emitted red and blue fluorescence. Cancer cells stained with triple colors blue, red and green, were dead cells progressing from apoptotic cell population. The cells were counted and apoptotic cells were expressed as percentage of total cells.

Expression of TRAIL death receptors. The cell surface expression of TRAIL death receptors, TRAIL-R1 and TRAIL-R2 on bladder cancer cells was measured by flow cytometry. The TCC cells were seeded in 24 -well plates for 24 hours. After the time, the

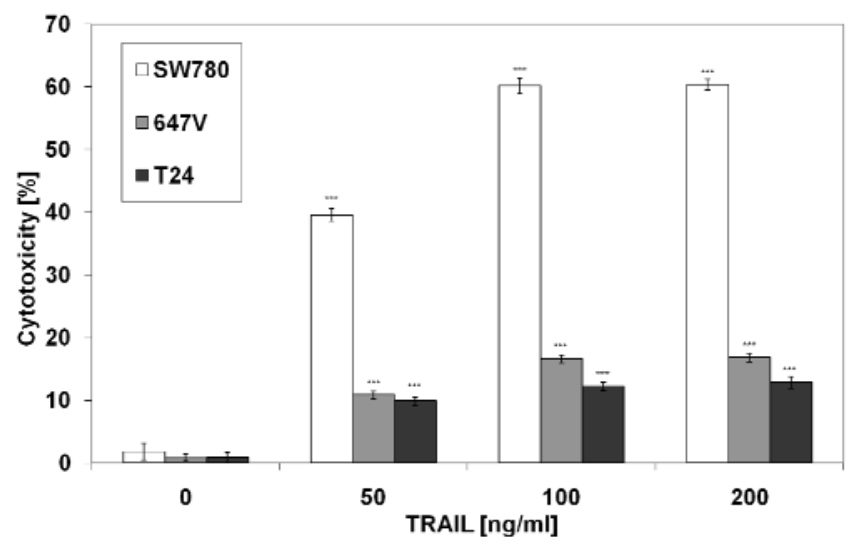

Fig. 1. TRAIL-induced cytotoxicity in bladder cancer cells. The cells incubated for 20 hours with TRAIL at concentrations of $0-200 \mathrm{ng} / \mathrm{ml}$. The percentage of cell death was measured by MTT cytotoxicity assay. The values represent mean $\pm \mathrm{SD}$ of three independent experiments performed in quadruplicate $(n=12)$. All differences are statistically significant in relation to control $(* * * \mathrm{p}<0.001)$.

cells were harvested with $0.05 \%$ trypsin/ $0.02 \%$ EDTA, washed twice in PBS and incubated for 30 minutes at $4^{\circ} \mathrm{C}$ with $10 \mu \mathrm{L}$ of phycoerythrin-conjugated monoclonal anti-human TRAIL-R1 or TRAIL-R2 antibody (R\&D Systems, Minneapolis, MN, USA). Cancer cells were then washed and samples were immediately used for flow cytometric analysis (BD FACScan, Becton Dickinson Immnunocytometry Systems, San Jose, CA, USA). The control consisted of cells in a separate tube treated with PE-labeled mouse $\operatorname{IgG}_{1}$ or mouse $\operatorname{IgG}_{2 \mathrm{~B}}$ (R\&D Systems, Minneapolis, MN, USA) [26].

Statistical analysis. The results are expressed as means $\pm \mathrm{SD}$ obtained from three separate experiments. The experimental means were compared to the means of untreated bladder cancer cells harvested parallelly and the data was polled for three replicate experiments performed in quadruplicate $(n=12)$. Statistical significance was evaluated using the one-way ANOVA followed by the post hoc test. $P$-values $<0.05$ were considered significant.

\section{Results \\ Cytotoxic effect of TRAIL on bladder cancer cells}

The bladder cancer cells were incubated with $50-200$ $\mathrm{ng} / \mathrm{ml}$ TRAIL for 20 hours. TRAIL at the concentration of $50-100 \mathrm{ng} / \mathrm{ml}$ induced cytotoxic effects on bladder cancer cells in a dose-dependent manner (Fig. 1). The SW780 cells were sensitive to TRAIL. In contrast, the two other bladder cancer cell lines, $647 \mathrm{~V}$ and T24, were resistant to TRAIL mediated cell death. The cytotoxicity measured by MTT assay after treatment with TRAIL at the concentration of $100 \mathrm{ng} / \mathrm{ml}$ was: $60.15 \pm 1.25 \%$ in SW780 cells, $16.62 \pm 0.61 \%$ in $647 \mathrm{~V}$ cells and $12.22 \pm 0.69 \%$ in T24 cells. The ligand concentration higher than $100 \mathrm{ng} / \mathrm{ml}$ had no significant influence on its cytotoxicity increase in relation to bladder cancer cells which were tested. TRAIL at the concentrations of $50-200 \mathrm{ng} / \mathrm{ml}$ did not induce the lysis of bladder cancer cells determined in the LDH test. 
A

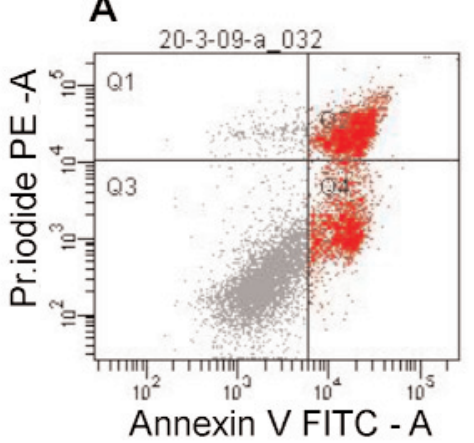

B

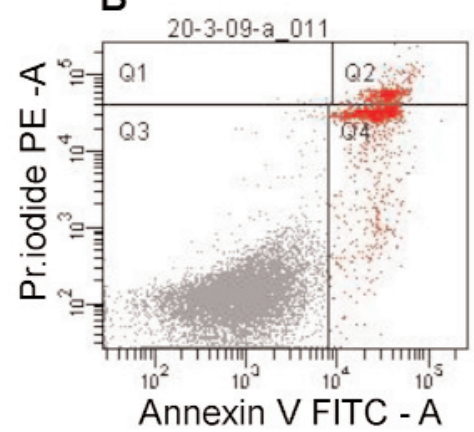

C

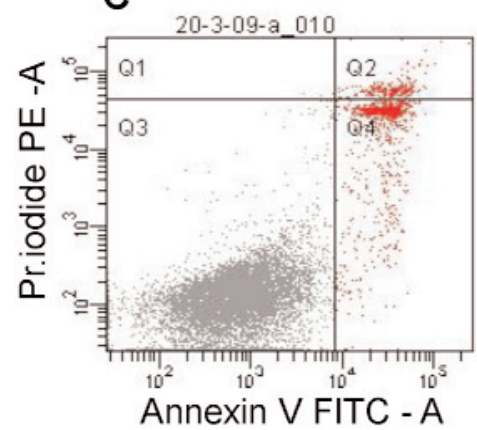

D

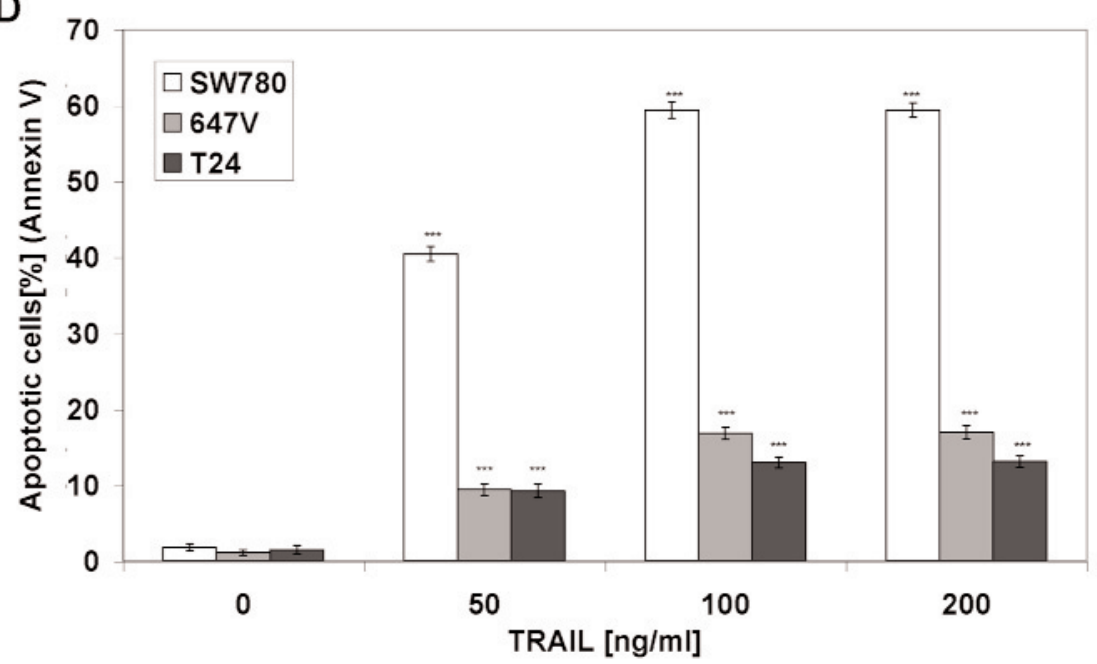

Fig. 2. TRAIL-induced apoptosis in bladder cancer cells. Bladder cancer cell cultures (A) SW780, (B) 647V and (C) T24 after 20-hour treatment with TRAIL at concentrations of $100 \mathrm{ng} / \mathrm{ml}$. (D) Apoptotic effect of $0-200 \mathrm{ng} / \mathrm{ml}$ TRAIL in bladder cancer cells. The cells incubated for 20 hours with TRAIL at concentrations of $0-200 \mathrm{ng} / \mathrm{ml}$. Detection of apoptotic cell death by annexin V-FITC staining using flow cytometry. The values represent mean \pm SD of three independent experiments performed in quadruplicate $(\mathrm{n}=12)$. All differences are statistically significant in relation to control $(* * * \mathrm{p}<0.001)$.

\section{TRAIL-induced apoptosis in bladder cancer cells}

TRAIL at the concentration of $50-100 \mathrm{ng} / \mathrm{ml}$ induced apoptosis on bladder cancer cells in a dose-dependent manner. Fig. 2 demonstrates the apoptotic effect of TRAIL at the concentrations of $50-200 \mathrm{ng} / \mathrm{ml}$ in cancer cells after 20-hour treatment measured by flow cytometry. The SW780 cells were shown to be sensitive to TRAIL induced apoptosis $(59.43 \pm 1.11 \%$ apoptotic cells after incubation with $100 \mathrm{ng} / \mathrm{ml}$ TRAIL). The $647 \mathrm{~V}$ and T24 cells were resistant to TRAIL mediated apoptosis $(16.86 \pm 0.82 \%$ and $13.01 \pm 0.71 \%$ apoptotic cells after incubation with $100 \mathrm{ng} / \mathrm{ml}$ TRAIL respectively). Fig. 3 shows the bladder cancer cells treated with $100 \mathrm{ng} / \mathrm{ml} \mathrm{TRAIL}$ for 20 hours observed under fluorescence microscopy. The apoptotic effect of

Table 1. The cell surface expression of death receptor TRAIL-R1 and TRAIL-R2 in bladder cancer cells. The values represent mean \pm SD of three independent experiments performed in quadruplicate $(\mathrm{n}=12)$.

\begin{tabular}{|c|c|c|c|}
\hline \multirow{2}{*}{$\begin{array}{l}\text { The cell surface } \\
\text { expression of } \\
\text { death receptor }\end{array}$} & \multicolumn{3}{|c|}{ Bladder cancer cells } \\
\hline & SW780 & $647 \mathrm{~V}$ & $\mathrm{~T} 24$ \\
\hline TRAIL-R1 & $4.96 \pm 1.25 \%$ & $1.13 \pm 0.92 \%$ & $2.36 \pm 1.14 \%$ \\
\hline TRAIL-R2 & $45.04 \pm 2.11 \%$ & $2.34 \pm 0.86 \%$ & $3.93 \pm 1.73 \%$ \\
\hline
\end{tabular}

TRAIL in bladder cancer cells was similar in both the flow cytometry and fluorescence microscopy. The treatment of bladder cancer cells with TRAIL at the concentration higher than $100 \mathrm{ng} / \mathrm{ml}$ had no significance on the death cells percentage.

\section{Expression of TRAIL-R1 and TRAIL-R2 on bladder cancer cells}

To identify the mechanism of TRAIL-sensitivity and TRAIL-resistance of bladder cancer cells, the cell surface expression of TRAIL death receptors, TRAIL-R1 and TRAIL-R2 were examined by flow cytometry (Table 1). The expression of TRAIL-R1 was detected in less than $5 \%$ of each bladder cancer cell line. In contrast, TRAIL-R2 is strongly expressed in TRAIL sensitive SW780 cells $(45.04 \pm 2.11 \%)$, whereas TRAILresistant $647 \mathrm{~V}$ and T24 cells are characterized by low expression of TRAIL-R2 $(2.34 \pm 0.86 \%$ and 3.93 $\pm 1.73 \%$ respectively).

\section{Discussion}

Soluble or expressed on immune cells (natural killer (NK) cells, lymphocytes T, monocytes, macrophages, dendritic cells and neutrophils) molecules of TRAIL play an important role in antitumor immunity, surveil- 

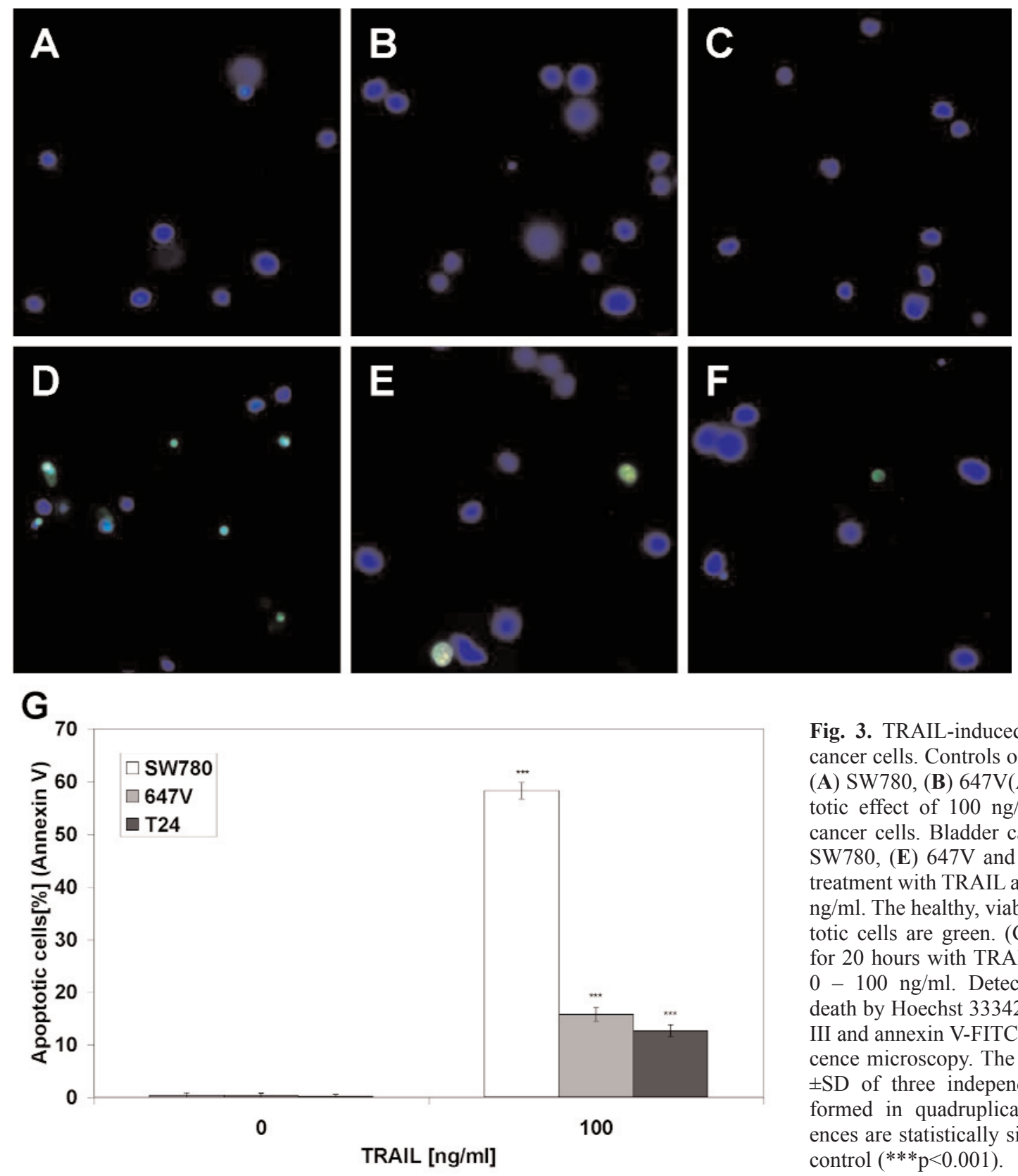

Fig. 3. TRAIL-induced apoptosis in bladder cancer cells. Controls of cells without TRAIL: (A) SW780, (B) 647V(A) and (C) T24. Apoptotic effect of $100 \mathrm{ng} / \mathrm{ml}$ TRAIL in bladder cancer cells. Bladder cancer cell cultures (D) SW780, (E) 647V and (F) T24 after 20-hour treatment with TRAIL at concentrations of 100 $\mathrm{ng} / \mathrm{ml}$. The healthy, viable cells are blue, apoptotic cells are green. $(\mathrm{G})$ The cells incubated for 20 hours with TRAIL at concentrations of $0-100 \mathrm{ng} / \mathrm{ml}$. Detection of apoptotic cell death by Hoechst 33342, ethidium homodimer III and annexin V-FITC staining using fluorescence microscopy. The values represent mean $\pm \mathrm{SD}$ of three independent experiments performed in quadruplicate $(n=12)$. All differences are statistically significant in relation to control $(* * * \mathrm{p}<0.001)$.

lance and defense mechanisms against tumor cells [5$7,14,18,27]$. Recombinant human TRAIL used in our study is a soluble protein based on a naturally occurring ligand. Numerous studies have shown that TRAIL induces apoptosis in a wide variety of cancer cells and significantly inhibits growth in xenograft tumor models [5-9].

TRAIL mediates apoptosis through two death receptors, TRAIL-R1 and TRAIL-R2, that are expressed in the cancer cells surface. The interaction of the ligand and death receptors leads to activation of the extrinsic apoptosis pathways $[1,11]$. However, some tumor cells are resistant to TRAIL-mediated cytotoxicity. Previous reports suggested that the sensi- tivity of cancer cells to TRAIL-induced apoptosis can be correlated to the relative expression of death receptors TRAIL-R1 and TRAIL-R2 or intracellular levels of antiapoptotic proteins [18-20].

The purpose of this study was to investigate the sensitivity of three human bladder transitional cell cancer lines to TRAIL-mediated apoptosis. We demonstrated that the moderately differentiated transitional $647 \mathrm{~V}$ cells and poorly differentiated transitional T24 cells are resistant to TRAIL, in contrast to well differentiated transitional SW780 cells sensitive to TRAIL-induced cytotoxicity. Our results from detection of apoptosis by flow cytometry and fluorescence microscopy with annexin V-FITC and the typical mor- 
phological changes determined by Hoechst 33342 confirmed that the mechanism of TRAIL mediated cytotoxicity on bladder cancer cells is apoptosis. Shimada et al., Earel et al. and Mizutani et al. confirmed that some bladder cancer lines, including T24 cells are resistant to TRAIL-induced apoptosis $[26,28,29]$.

Sensitivity of cancer cells to TRAIL induced apoptosis can be modulated at several levels in the apoptosis signaling pathways [19]. Numerous mechanisms of cancer cells escape from apoptosis induction have been described. The increased expression and mutation of TRAIL death receptors in cancer cells are the main reason of TRAIL-resistance. The efficacy of correlates with the cell surface expression of TRAIL-R1 and/or TRAIL-R2 in cancer cells has been shown [30]. The upregulation of TRAIL-R1 and/or TRAIL-R2 expression in tumor cells by anticancer agents overcome the resistance to TRAIL-mediated apoptosis in cancer cells [18]. We showed that TRAIL-sensitive SW780 bladder cancer cells expressed high levels of death receptor TRAIL-R2 on its surface. The TRAILresistant $647 \mathrm{~V}$ and T24 cells characterized low expression of TRAIL-R2.

The cell surface expression of TRAIL-R2 is essential for TRAIL-induced apoptosis. The TRAIL-R2 gene is located at 8p21-22 and this region is frequently lost in bladder cancer [31]. The chemotherapeutic drugs or ionizing radiation induce expression of TRAIL-R2 in cancer cells surface enhancing the therapeutic potential of TRAIL $[17,21,30]$.

Furthermore, upregulation expression of TRAIL-R2 by doxorubicin, cisplatin and topotecan in renal cancer cells, doxorubicin and etoposide in leukemia cells and glioma cells, irinotecan in colon cancer cells enhanced the responsiveness of these tumor cells to TRAILmediated apoptosis [32-37]. In in vitro study, receptor TRAIL-R2 contributed to TRAIL-mediated apoptosis in combination with ionizing radiation [38]. Interferonalpha sensitizes human hepatoma cells to TRAILinduced apoptosis through DR5 upregulation [39]. Histone deacetylase inhibitors modulate the sensitivity of bladder by increased TRAIL-R2 gene transcription that correlates with increased TRAIL-R2 surface expression [29]. These observations, including ours, suggest that TRAIL-R2 expression might be a reliable indicator of the cytotoxic effect that could be achieved by recombinant soluble TRAIL or agonistic anti-TRAIL-R2 [18].

TRAIL as recombinant soluble TRAIL or agonistic anti-TRAIL-R1 and anti-TRAIL-R2 antibodies were introduced in phases I and II of the studies. Although the clinical trials demonstrate promising results, the use of TRAIL therapies is only advantageous to patient with TRAIL-sensitive tumors. This fact showed that TRAIL as monotherapy will only be effective against TRAIL-sensitive cancer cells, however most tumors are resistant to TRAIL induced apoptosis. TRAIL resistance has been reported in approximately $50 \%$ of tested tumor cell lines thus limiting the use of TRAIL alone in clinic $[14,17,18]$.

In phase II of the studies the patients with TRAILresistant tumors required the combination of sensitizing agents (chemotherapy or radiotherapy) and TRAIL to reverse resistance. Targeted induction of apoptosis in cancer cells by activation of the death receptors, particularly TRAIL-R2, should be an ideal therapeutic strategy to eliminate cancer cells $[18,40]$. The cytotoxic agents capable of up-regulating the expression of TRAIL-R2 can sensitize cancer cells to TRAIL induced apoptosis. Therefore, receptor TRAIL-R2 is an attractive therapeutic target in cancer treatment.

\section{References}

[ 1] Suliman A, Lam A, Datta R, Srivastava RK. Intracellular mechanisms of TRAIL: apoptosis through mitochondrialdependent and -independent pathways. Oncogene. 2001;20: 2122-2133.

[ 2] Gaur U, Aggarwal BB. Regulation of proliferation, survival and apoptosis by members of the TNF superfamily. Biochem Pharmacol. 2003;66:1403-1408.

[ 3] Rzeszutko M, Rzeszutko W, Dzięgiel P, Balcerzak W, Kaliszewski K, Bolanowski M. Expression of FAS/APO1/CD95 in thyroid tumors. Folia Histochem Cytobiol. 2007;45:87-91.

[4] Wiley S, Schooley K, Smolak P, Din W, Huang C, Nicholl J, Sutherland G, Smith T, Rauch C, Smith C. Identification and characterization of a new member of the TNF family that induced apoptosis. Immunity. 1995;3:673-682.

[ 5] Almasan A, Ashkenazi A. Apo2L/TRAIL: apoptosis signaling, biology and potential for cancer therapy. Cytokine Growth Factor Rev. 2003;14:337-348.

[ 6] Pitti RM, Marsters SA, Ruppert S, Donahue CJ, Moore A, Ashkenazi A. Induction of apoptosis by Apo-2 ligand, a new member of the tumor necrosis factor receptor family. $\mathrm{J} \mathrm{Biol}$ Chem. 1996;271:12687-12690.

[ 7] Ashkenazi A, Pai R, Fong S, Leung S, Lawrence D, Marsters S, Blackie C, Chang L, McMurtrey AE, Hebert A, DeForge L, Koumenis I, Lewis D, Harris D, Bussiere J, Koeppen H, Shahrokh Z, Schwall RH. Safety and antitumor activity of recombinant Apo2 ligand. J Clin Invest. 1999;104:155-162.

[ 8] Kelley SK, Harris LA, Xie D, Deforge L, Totpal K, Bussiere J, Fox J. Pre-clinical studies to predict the disposition of Apo2L/tumor necrosis factor-related apoptosis-inducing ligand in humans: characterization of in vivo efficacy, pharmacokinetics, and safety. J Pharmacol Exp Ther. 2001;299:31-38.

[ 9] Walczak H, Miller RE, Ariail K, Gliniak B, Griffith TS, Kubin M, Chin W, Jones J, Woodward A, Le T, Smith C, Smolak P, Goodwin RG, Rauch CT, Schuh JC, Lynch DH. Tumoricidal activity of tumor necrosis factor-related apoptosis-inducing ligand in vivo. Nature Med. 1999;5:157-163.

[10] Pan G, Ni J, Wei YF, Yu G, Gentz R, Dixit V. An antagonist decoy receptor and a death domain-containing receptor for TRAIL. Science. 1997;277:815-818.

[11] Pan G, O'Rourke K, Chinnaiyan AM, Gentz R, Ebner R, Ni J, Dixit V. The receptor for the cytotoxic ligand TRAIL. Science. 1997;276:111-113.

[12] Walczak H, Degli-Eposti MA, Johnson RS, Smolak PJ, Waugh JY, Boiani N, Timour MS, Gerhart MJ, Schooley KA, Smith CA, Goodwin RG, Rauch CT. TRAIL-R2: a novel apoptosismediating receptor for TRAIL. EMBO J. 1997;16: 5386-5397. 
[13] Sheridan JP, Marsters SA, Pitti RM, Gurney A, Skubatch M, Baldwin D, Ramakrishnan L, Gray CL, Baker K, Wood WI, Goddard AD, Godowski P, Ashkenazi A. Control of TRAILinduced apoptosis by a family of signaling and decoy receptors. Science. 1997;277:118-121.

[14] Kruyt FA. TRAIL and cancer therapy. Cancer Lett. 2008;263: $14-25$.

[15] Colombel M, Soloway M, Akaza H, Bohle A, Palou J, Buckley R, Lamm D, Brausi M, Witjes A, Persad R. Epidemiology, staging, grading, and risk stratification of bladder cancer. Eur Urol 2008;7:618-626.

[16] Yagita H, Takeda K, Hayakawa Y, Hayakawa Y, Smyth MJ, Okumara K. TRAIL and its receptors as targets for cancer therapy. Cancer Sci. 2004;95:777-783.

[17] Duiker EW, Mom CH, Jong S, Willemse PH, Gietema JA, Zee AG, Vries EG. The clinical trail of TRAIL. Eur $J$ Cancer. 2006;42:2233-3340.

[18] Thorburn A, Behbakht K, Ford H. TRAIL receptor - targeted therapeutics: resistance mechanisms and strategies to avoid them. Drug Resist Updat. 2008;11:17-24.

[19] Griffith TS, Lynch D. TRAIL: a molecule with multiple receptors and control mechanisms. Curr Opin Immunol. 1998;10: 559-563.

[20] Zhang L, Fang B. Mechanisms of resistance to TRAIL-induced apoptosis in cancer. Cancer Gene Ther. 2005;12:228-227.

[21] Shankar S, Srivastava RK. Enhancement oh therapeutic potential of TRAIL by cancer chemotherapy and irradiation: mechanisms and clinical implications. Drug Resist Updat. 2004; 7:139-156.

[22] Szliszka E, Majcher A, Domino M, Pietsz G, Król W. Cytotoxic activity of tumor necrosis factor-related apoptosis-inducing ligand (TRAIL) against bladder cancer cells after using chemotherapeutic drugs. Polish J Urol. 2007;60:138-142.

[23] Kisielewska J, Ligęza J, Klein A. The effect of tyrosine kinase inhibitors, tyrphostins: AG1024 and SU1498, on autocrine growth of prostate cancer cells (DU145). Folia Histochem Cytobiol. 2008;46:185-191.

[24] Szliszka E, Czuba ZP, Jernas K, Krol W. Dietary flavonoids sensitize HeLa cells to tumor necrosis factor-related apoptosis-inducing ligand (TRAIL). Int J Mol Sci 2008;9:56-64.

[25] Szliszka E, Czuba ZP, Domino M, Mazur B, Zydowicz G, Krol W. Ethanolic extract of propolis (EEP) enhances the apoptosis-inducing potential of TRAIL in cancer cells. Molecules 2009;14:738-754.

[26] Shimada O, Wu X, Jin X, Nouh MA, Fiscella M, Albert V, Matsuda T, Kakehi Y. Human agonistic antibody to tumor necrosis factor-related apoptosis-inducing ligand receptor 2 induces cytotoxicity and apoptosis in prostate cancer and bladder cancer cells. Urology. 2007;69:395-401.

[27] Jablonska E, Jablonski J, Marcinczyk M, Grabowska Z, Piotrowski L. The release of soluble forms of TRAIL and DR5 by neutrophils of oral cancer patients. Folia Histochem Cytobiol. 2008;46:177-183.

[28] Mizutani Y, Nakao M, Ogawa O, Yoshida O, Bonavida B, Miki T. Enhanced sensitivity of bladder cancer cells to tumor necro- sis factor related apoptosis inducing ligand mediated apoptosis by cisplatin and carboplatin. J Urol. 2001;165:263-270.

[29] Earel JK, VanOosten RL, Griffith TS. Histone deacetylase inhibitors modulate the sensitivity of tumor necrosis factorrelated apoptosis-inducing ligand - resistant bladder tumor cells. Cancer Res. 2006;66:499-507.

[30] O'Kane HF, Watson CJ, Johnston SR, Petak I, Watson WG, Williamson. Targeting death receptors in bladder, prostate and renal cancer. $J$ Urol. 2006;175:432-438.

[31] Choi C, Kim MH, Juhng SW, Oh BR. Loss of heterozygosity at chromosome segments 8p22 and 8p11.2-21.1 in transitional cell carcinoma pf urinary bladder. Int J Cancer. 2000;86: 501-507.

[32] Nagane M, Pan G, Weddle JJ, Dixit VM, Cavenee WK, Huang HJ. Increased death receptor 5 expression by chemotherapeutic agents in human glioma causes synergistic cytotoxicity with tumor necrosis factor-related apoptosis-inducing ligand in vitro and in vivo. Cancer Res. 2000;60:847-853.

[33] Dejosez M, Ramp U, Mahotka C, Krieg A, Walczak H, Gabbert HE, Garharz CD. Sensitivity to TRAIL/APO2L-mediated apoptosis in human renal cell carcinoma and its enhancement by topotecan. Cell Death Differ. 2000;7:1127-1136.

[34] Wen J, Ramadevi N, Nguyen D, Perkins C, Worthington E, Bhalla K. Antileukemic drug increase death receptor 5 levels and enhance APO-2L-induced apoptosis oh human leukemia cells. Blood. 2000;96:3900-3906.

[35] Naka T, Sagamura K, Hylander BL, Widmer MB, Rustum YM, Rapasky EA. Effects of tumor necrosis factor-related apoptosis-inducing ligand alone and in combination with chemotherapeutic agents on patients' colon tumors grown in SCID mice. Cancer Res. 2002;62:5800-5806.

[36] Wu XX, Jin XH, Zeng Y, El Hamed AM, Kakehi Y. Low concentrations of doxorubicin sensitizes human solid cancer cells to tumor necrosis factor-related apoptosis-inducing ligand (TRAIL) - receptor R2 - mediated apoptosis by inducing TRAIL-R2 expression. Cancer Sci. 2007;98:1969-1976.

[37] Wu XX, Kakehi Y. Enhancement of lexatumumab-induced apoptosis in human solid cancer cells by cisplatin in caspasedependent manner. Clin Cancer Res. 2009;15:2039-2047.

[38] Hamasu T, Inanami O, Asanuma T, Kuwabara M. Enhanced induction of apoptosis by combined treatment of human carcinoma cells with $\mathrm{X}$ rays and death receptor agonists. $J$ Radiat Res. 2005;46:103-110.

[39] Shigeno M, Nakao K, Ichikawa T, Suzuki K, Kawakami A, Abiru S, Miyazoe S, Nakagawa Y, Ishikawa H, Hamasaki K, Nakata K, Ishii N, Eguchi K. Interferon-alpha sensitizes human hepatoma cells to TRAIL-induced apoptosis through DR5 upregulation and NF-kappa B inactivation. Oncogene. 2003;22:1653-1662.

[40] Wu GS. TRAIL as a target in anti-cancer therapy. Cancer Lett. 2009 ; in press.

Submitted: 1 June, 2009 Accepted after reviews: 16 September, 2009 